\title{
Estudo farmacobotânico comparativo entre Nicandra physalodes e Physalis angulata (Solanaceae)
}

\author{
K. Nurit Silva ${ }^{1}$, M.F. Agra* \\ Laboratório de Tecnologia Farmacêutica Prof. Delby Fernandes de Medeiros, Universidade Federal da Paraíba, \\ Caixa Postal 5009, 58015-970, João Pessoa, PB, Brasil
}

\begin{abstract}
RESUMO: Neste trabalho realizou-se uma caracterização morfoanatômica comparativa, entre as folhas de Nicandra physalodes (L.) Gaertn. e Physalis angulata L. (Solanaceae), espécies de uso na medicina popular, cujas folhas e raízes são indicadas como diurético e antitérmico. As identificações botânicas e as morfodiagnoses macroscópicas foram realizadas após estudos morfológicos. Para as morfodiagnoses microscópicas realizaram-se cortes paradérmicos e transversais das folhas (lâmina e pecíolo), clarificados e posteriormente corados com safranina e safrablue. Além dos caracteres morfológicos da flor e do fruto, as duas espécies diferem pelos seguintes caracteres: vascularização da nervura principal em forma de arco em $N$. physalodes, e semicircular em P. angulata; drusas no mesofilo de $P$. angulata; tricomas glandular-estipitados com a glândula apical bisseriada em $N$. physalodes. As duas espécies distinguem-se principalmente pela morfologia da flor e fruto e pela anatomia do mesofilo e vascularização da nervura principal.
\end{abstract}

Unitermos: Nicandra physalodes, Physalis angulata, Solanaceae, farmacobotânica, plantas medicinais.

\begin{abstract}
Comparative pharmacobotanical study on Nicandra physalodes and Physalis angulata (Solanaceae)". In this work a morphoanatomical comparative characterization was carried out between the leaves of Nicandra physalodes (L.) Gaertn. and Physalis angulata L. (Solanaceae) species used in folk medicine, whose leaves are indicated as diuretic and febrifuge. The botanical identification and macroscopical morphodiagnosis were made after morphological studies. The microscopical morphodiagnosis were carried out by paradermic and transversal cuts of the leaves (blade and petiole), clarified and coloured with safranin and astrablue. Moreover the morphological characters of the flower and fruit, of the two species can be distinguished by the following characters: $N$. physalodes has the bundle vascular of the middle vein in arc format; $P$. angulata has the vascular bundle of the middle vein in a semi-circle format; druses in the mesophyll of $P$. angulata; and the presence of trichomes glandular-estipitate with bisseriate head in $N$. physalodes. The morphology of flower and fruit and the anatomy of mesophyll, the vascular bundles of middle vein are the principal distinctive characters between them.
\end{abstract}

Keywords: Nicandra physalodes, Physalis angulata, Solanaceae, pharmacobotany, medicinal plants.

\section{INTRODUÇÃO}

A família Solanaceae A. L. Jussieu é uma das maiores e mais complexas dentre as Angiospermas, com 92 gêneros e cerca de 2.300 espécies, tendo a América do Sul como um dos principais centros de diversidade e endemismo (Hunziker, 2001).

É um grupo de grande importância econômica, possuindo espécies empregadas na alimentação humana, como a batatinha e o tomate (espécies de Solanum), produtoras de substâncias de uso farmacêutico, como atropina e a hiosciamina, isoladas de Atropa belladonna L. e Hyocyamus niger L., respectivamente, além de possuir espécies ornamentais (espécies de Petunia, Brugmansia e Brunfelsia) (Agra, 2000).

Os gêneros Nicandra Adans. e Physalis L. pertencem à subfamília Solanoideae e compartilham os seguintes caracteres: hábito herbáceo a arbustivo; androceu pentâmero com anteras com aberturas longitudinais; ovário com disco basal e fruto baga, envolvido pelo cálice acrescente e inflado.

Nicandra é um gênero monotípico, originário da América do Sul, naturalizado nas regiões tropicais do mundo. Physalis possui cerca de 90 espécies, com distribuição cosmopolita tropical, ocorrendo desde o sul da América do Norte até a América do Sul, com centros de diversidade no México, Estados Unidos e na América Central (Hunziker, 2001), tendo algumas espécies cultivadas por sua importância na alimentação humana.

Espécies de Nicandra e Physalis são consideradas medicinais e tóxicas em vários países das Américas, África e Ásia, destacando-se pela presença de vitaesteróides, como nicandrenona, vitanolídeo, fisalinas e neofisalinas (Tomassini et al., 2000), com atividades antineoplásica e antitumoral, e pelos alcalóides tropânicos e pirrolidínicos, como higrina e tropinona 
(Romeike, 1965, 1966). Considerando-se o nível de oxidação biogenética, Physalis é o gênero mais derivado nas Solanaceae, e ocupa lugar de destaque na família pela presença de metabólitos poli-oxigenados e vitaesteróides (Tomassini et al., 2000), substâncias às quais se atribui várias atividades farmacológicas. Em trabalhos anteriores observou-se que Physalis angulata possui atividade antineoplásica (Ribeiro et al.,2002).

Physalis angulata L. e Nicandra physalodes (L.) Gaertn. são largamente empregadas na medicina popular de todo o mundo, principalmente da América do Sul, como o Peru (Duke; Vasquez, 1994), Colômbia (Barriga, 1975), Suriname (Hasrat et al., 1997) e Brasil (Agra et al., 1994). Embora sejam espécies de importância na etnomedicina, cujo potencial farmacológico é reconhecido, evidenciouse a ausência de estudos farmacobotânicos para estas espécies.

Neste trabalho apresenta-se um estudo farmacobotânico comparativo das folhas de Nicandra physalodes e Physalis angulata, com morfodiagnoses macroscópicas e microscópicas que possibilitam seu reconhecimento morfo-anatômico, dando continuidade ao projeto de estudos farmacobotânicos das plantas usadas na medicina popular do Nordeste do Brasil (Cabral; Agra, 1998, 1999; Freitas; Agra 2002; Silva; Agra, 2002; Silva; Agra; Baracho, 2002; Basílio et al., 2003; Leal; Agra, 2005).

\section{MATERIAL E MÉTODOS}

\section{Coletas e identificações botânicas}

Realizaram-se coletas e observações de campo para as identificações, estudos morfológicos e anatômicos. Uma parte das amostras foi fixada em álcool a $70^{\circ}$ G.L.; a outra parte foi herborizada, seguindo-se a metodologia descrita por Forman e Bridson (1989), sendo as exsicatas depositadas no Herbário Prof. Lauro Pires Xavier (JPB), com duplicatas na coleção de referência do Laboratório de Tecnologia Farmacêutica Prof. Delby Fernandes de Medeiros (LTF). As identificações foram realizadas com auxílio de chaves analíticas, diagnoses e descrições, encontradas na bibliografia especializada (Sendtner, 1846; Dunal, 1852; Smith; Downs, 1966; Nee, 1986; Hunziker, 2001), e complementadas pelas análises dos tipos do herbário do Museu de História Natural de Estocolmo (S-LINN). As morfodiagnoses e ilustrações foram realizadas com a análise de amostras frescas, fixadas em álcool a 70 G.L., e exsicatas dos herbários JPB e Prof. Dárdano de Andrade Lima (IPA), do Instituto de Pesquisas Agropecuárias de Pernambuco, com auxílio de estereomicroscópio binocular e câmara-clara Zeiss. As abreviaturas dos autores estão de acordo com Brummitt e Powell (1992).

\section{Estudos anatômicos}

Realizaram-se cortes paradérmicos da lâmina foliar à mão livre (faces adaxial e abaxial). Cortes transversais foram realizados, à mão livre, para estudos do mesofilo e da vascularização no 1/3 mediano da lâmina foliar e nas áreas basal, mediana e apical do pecíolo, com apoio do pecíolo de Cecropia (imbaúba). Os cortes foram clarificados com cloral hidratado, sendo os paradérmicos corados com safranina e os cortes transversais com safrablue, montados entre lâmina e lamínula, com glicerina a 50\%. A classificação dos estômatos baseouse em Metcalfe e Chalk (1979) e a caracterização das paredes celulares, mesofilo e dos tricomas baseou-se em Fahn (1974). As estruturas foram observadas e ilustradas ao microscópio óptico, com câmara clara Zeiss. As fotomicrografias foram realizadas ao microscópio óptico, Olympus CH30, com câmara fotográfica Olympus PM -BP35.

\section{RESULTADOS}

Nicandra physalodes (L.) Gaertn. e Physalis angulata L. são espécies cujas folhas e raízes são comumente empregadas na medicina popular do Nordeste do Brasil.

Physalis pertence á tribo Solaneae G. Don, subtribo Physalinae, caracterizando-se pela presença de cálice com segmentos não auriculados, filetes não geniculados na base, anteras dorsifixas, basifixas ou dorsibasifixas, e gineceu bicarpelar. Por outro lado, Nicandra é um gênero da tribo monotípica Nicandreae Wettst., cujo cálice possui segmentos auriculados, filetes geniculados e expandidos na base, anteras basifixas e o gineceu 4-5 carpelar (Hunziker, 2001).

\section{Nicandra physalodes (L.) Gaertn. Fruct. Sem. Pl. 2: 237, t. 131, f. 2.1791.}

Sinônimos. Atropa physalodes L. Sp. Pl., 1: 181-182. 1753; Boberella nicandra Krause Deutschl. Fl., Abt. II, Cryptog. 10: 61. 1903; Nicandra minor Hort. ex Fisch. Index Sem. (St. Petersburg) 9: 81. 1843; Physalis daturaefolia Lam. Encycl. 2: 102. 1786; Physalodes peruviana Kuntze Revis. Gen. P1. 2: 452.1891.

Nomes vernaculares. Quintilho (Smith; Downs, 1966; Correa, 1974; Kissmann; Groth, 1995), joá-de-capote, bexiga, balãozinho, lanterna-da-china (Kissmann; Groth, 1995).

Descrição morfológica. Subarbusto, ca. $1,0 \mathrm{~m}$ de altura. Folhas alternas, glabrescentes, tricomas simples, glandulares e eglandulares; pecíolo $0,7-3,0 \mathrm{~cm}$, alado, canaliculado; lâmina 2,7-14,0 x 0,7-5,5 cm, elíptica a oval, membranácea, ápice agudo a acuminado, base atenuada, margem sinuosa a denteada. Pedicelo cilíndrico, 1,32,0 cm, glabrescente. Flores solitárias, axilares; cálice 
campanulado, sépalas-5, soldadas no 1/4 basal, ca. 2,5$5,0 \mathrm{~mm}$, lobos ovais a auriculados, 1,5-3,0 x 0,5-1,2 $\mathrm{cm}$, cuspidados no ápice, sagitados na base, ampliados no fruto, 2,5-3,0 x 1,0-20,0 cm; corola campanulada, coloração rósea a lilás, com máculas púrpuras na base, tubo 1,0-2,0 cm, 5-lacínios ca. 3,8-4,0 mm, oval-elípticos. Estames-5, anteras oblongas, 3,0-3,5 mm, basifixas; filetes cilíndricos, ca. 3,7-4,0 mm, geniculados, com tricomas simples na base. Ovário oval-cônico, 2,8-3,0 $\mathrm{mm}$, tetralocular, pluriovular; estilete filiforme, ca. 3,0$3,2 \mathrm{~mm}$, puberulento até o $1 / 4$ apical; estigma capitado; disco hipógino, 3,0-3,5 $\mathrm{mm}$ diâmetro e $1,5 \mathrm{~mm}$ de espessura. Baga globosa, ca. 0,8-1,0 cm, envolvida pelo cálice acrescente, inflado; sementes numerosas, ca. 1,0 $\mathrm{mm}$, subdiscóides, testa reticulado-foveolada, ferrugíneas a marrons (Fig. 1).

Descrição anatômica. A lâmina foliar de Nicandra

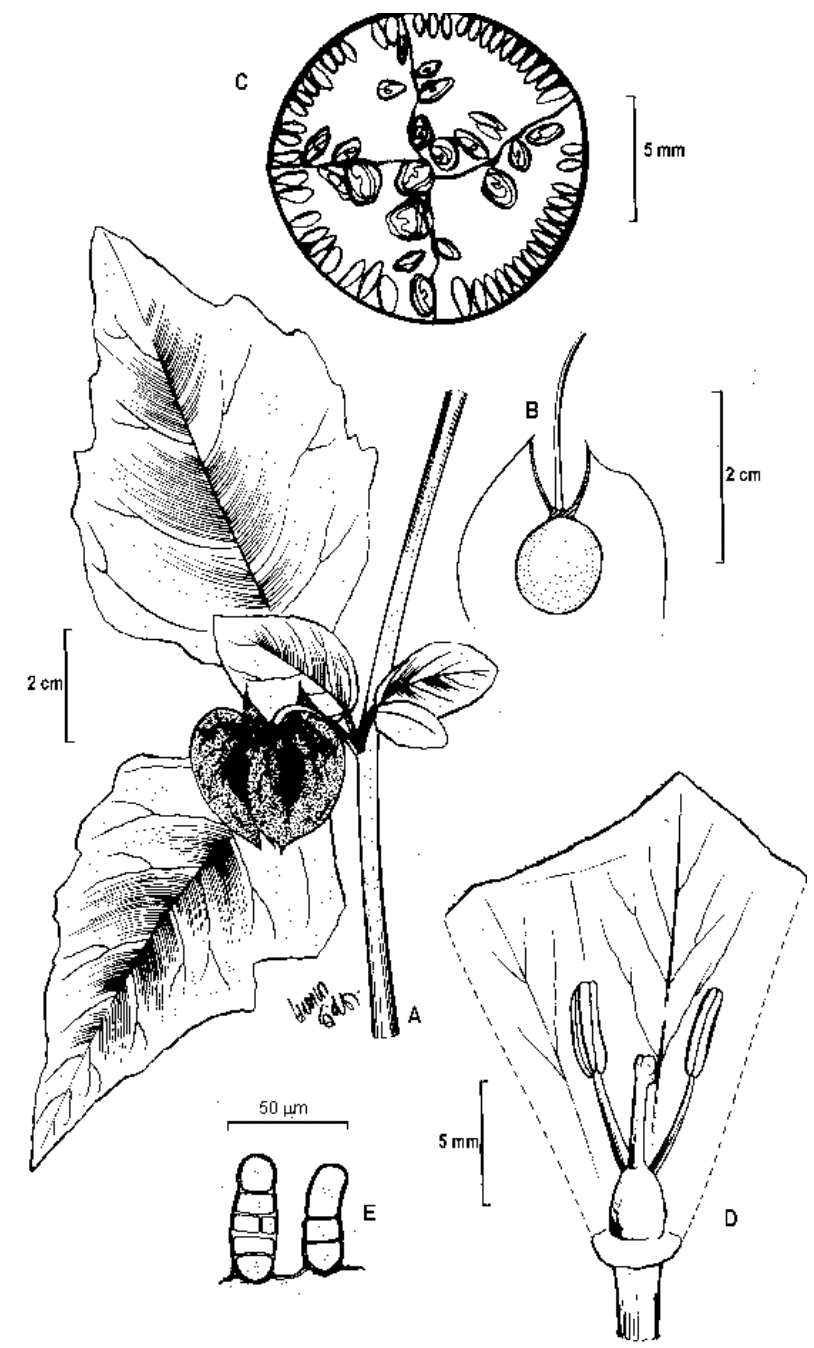

Figura 1. Nicandra physalodes (L.) Gaertn. (Agra et al. 5786). A. ramo frutificado; B. esquema do fruto com cálice acrescente, em secção longitudinal; C. secção transversal do fruto; D. detalhe da corola mostrando gineceu e androceu; E. tricomas da lâmina foliar. physalodes é anfiestomática e o mesofilo é heterogêneo e dorsiventral (Fig. 2). Em vista frontal, a face adaxial da epiderme apresenta células de paredes anticlinais ondeadas e espessadas (Fig. 3A) e a face abaxial células igualmente ondeadas e de paredes anticlinais mais delgadas (Fig. 3B). Os estômatos são dos tipos anisocítico e anomocítico em ambas as faces, ocorrendo em maior número na face abaxial. Nesta face as células-guarda também apresentam paredes anticlinais mais delgadas. Em secção transversal, a epiderme é uniestratificada (Fig. 2). Na face adaxial as células são tabulares e apresentam paredes periclinais convexas, sendo algumas externas angulosas e revestidas por uma cutícula lisa. $\mathrm{Na}$ face abaxial as células são poligonais, têm maior diâmetro e a cutícula é lisa, visivelmente mais delgada. Os estômatos, observado em secção transversal, apresentam espessamento nas paredes internas e grande afinidade tintorial. Apenas na face abaxial localizam-se um pouco abaixo do nível da epiderme. O parênquima paliçádico é uniestratificado e parênquima esponjoso é formado por três a cinco camadas, com células de diversos formatos, resultando em espaços irregulares, onde são encontrados feixes vasculares envoltos por bainha (Fig. 2).

A epiderme na região da nervura principal, quando observada tanto em vista frontal quanto em secção transversal, apresenta tricomas eglandulares, pluricelulares, unisseriados, e glandulares (Fig. 1E), estes do tipo glandular-estipitado, com a glândula apical pluricelular, bisseriada (Fig. 3A). A nervura principal (Fig. 4A), exibe contorno biconvexo, com raio menor na face adaxial, sendo proeminente na face abaxial. Adjacente à epiderme, evidencia-se o colênquima do tipo angular, com dois a quatro estratos celulares na região periférica de ambas as faces. O parênquima fundamental é constituído por células esféricas e hexagonais. O sistema vascular é formado por um único feixe bicolateral em

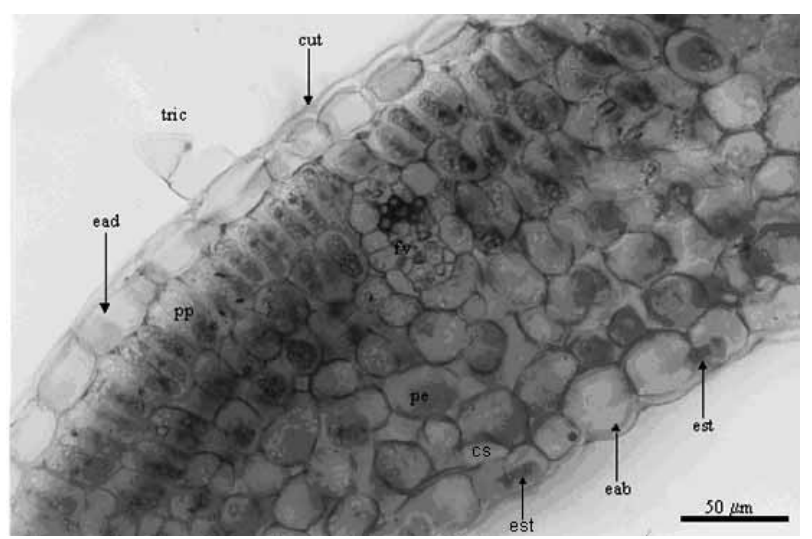

Figura 2. Nicandra physalodes (L.) Gaertn. (Agra et al. 5786). Secção transversal da lâmina foliar. Legendas: tric $=$ tricoma; $c$ cut $=$ cutícula; ead $=$ epiderme na face adaxial; $p p=$ parênquima paliçádico; $f v=$ feixe vascular; $\mathrm{pe}=$ parênquima esponjoso; eab $=$ epiderme na face abaxial; est= estômato; cs= câmara subestomática. 

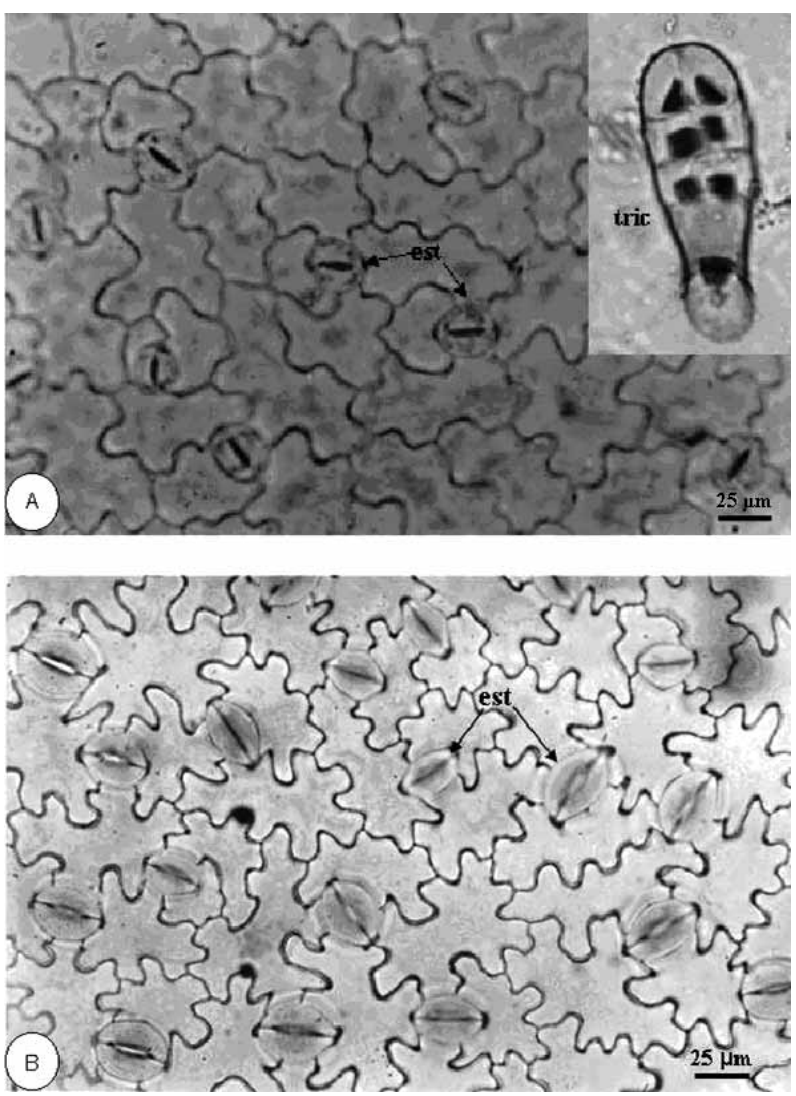

Figura 3. Nicandra physalodes (L.) Gaertn. (Agra et al. 5786). A-B. epiderme da lâmina foliar em vista frontal. A. face adaxial, células com paredes ondeadas, estômatos anomocíticos e anisocíticos e detalhe do tricoma glandular-estipitado; B. face abaxial, células com paredes ondeadas e estômatos anomocíticos e anisocíticos. Legendas: est $=$ estômatos; tric $=$ tricoma.

arco aberto, com numerosos elementos de vaso dispostos radialmente, e com células floemáticas organizadas em cordões de cinco a sete extratos celulares.

O pecíolo (Fig. 4B), em secção transversal, exibe contorno biconvexo, com duas pequenas alas laterais, e o diâmetro varia de acordo com a altura do corte, diminuindo em direção à região proximal. A epiderme é uniestratificada, revestida por uma cutícula lisa e espessa sobre as paredes periclinais externas. $\mathrm{O}$ córtex é preenchido pelo colênquima subepidérmico, do tipo angular, formado por dois a três estratos circulares nas camadas mais externas, e pelo parênquima fundamental, formado por células de contorno arredondado, seguido do cilindro vascular. A transição das células colenquimáticas para células parenquimáticas é marcada por uma diminuição gradual no espessamento da parede destas células. A vascularização apresenta-se constituída de quatro feixes bicolaterais, sendo dois grandes centrais, ovais, e dois pequenos laterais, nas alas, arredondados. Tricomas eglandulares distribuem-se esparsamente ao longo do pecíolo.
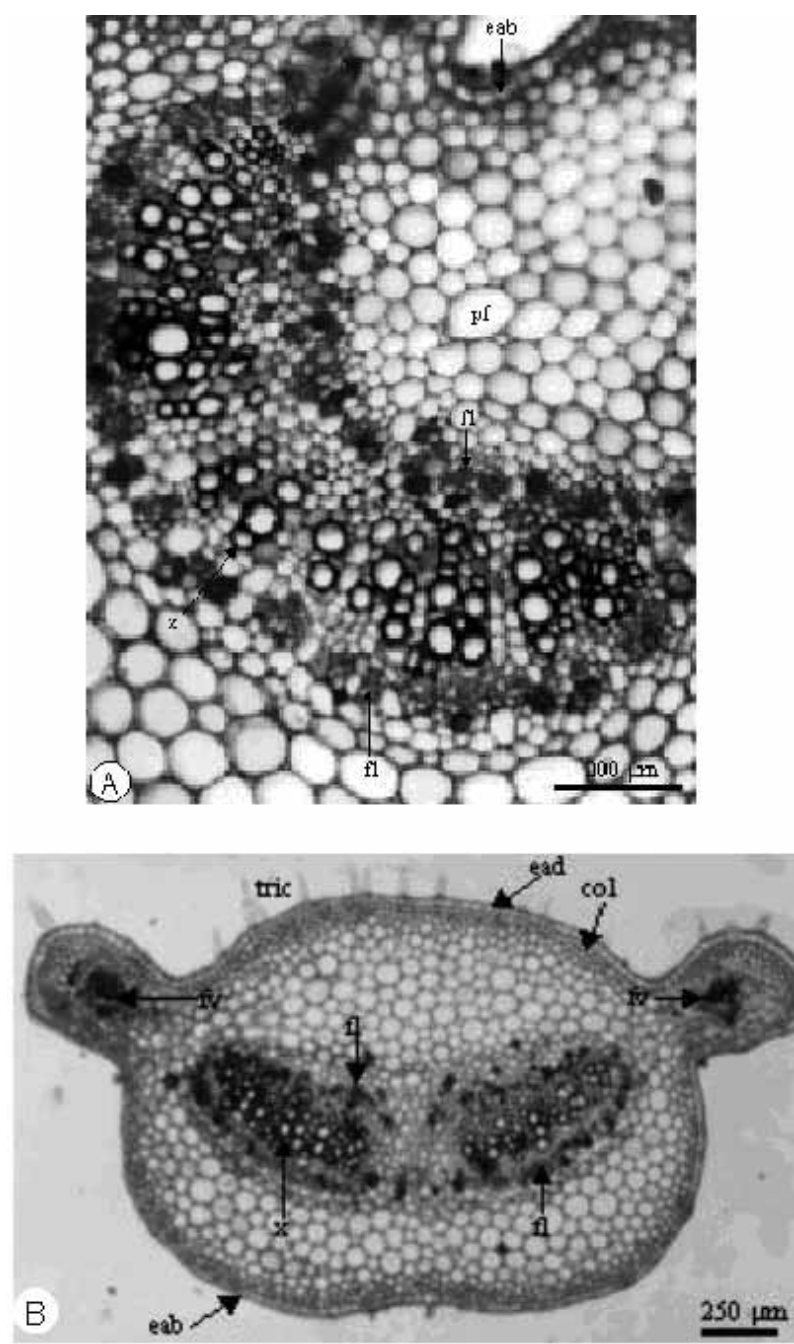

Figura 4. Nicandra physalodes (L.) Gaertn. (Agra et al. 5786). A. detalhe da secção transversal da nervura principal da lâmina foliar, evidenciando um feixe vascular bicolateral. B. secção transversal do pecíolo, região mediana, com quatro feixes bicolaterais. Legendas: tric $=$ tricoma; ead= epiderme na face adaxial; $c o l=$ colênquima; $\mathrm{fl}=$ floema; $\mathrm{x}=$ xilema; $\mathrm{fv}=$ feixe vascular; $\mathrm{pf}=$ parênquima fundamental; eab= epiderme na face abaxial.

Material examinado. BRASIL. Paraíba: Campina Grande, 16/VII/1979, Agra 130 (JPB); ibid., Bodocongó, 29/IX/1948, Xavier s.n. (JPB); ibid., Distrito de São José da Mata, 06/09/1982, Agra 396 (JPB); ibid., Fazenda Pedro da Costa Agra, 28/VI/1991, Agra 1317 (JPB); ibid., 03/V/2004, Agra et al. 6140 (JPB); Maturéia, Pico do Jabre, 13-14/IV/2002, Agra et al.. 5786 (JPB); Pernambuco: Brejo da Madre de Deus, 6/VIII/1968, Lira 68-287 (IPA); Triunfo, 26/II/1986, Gallindo 183 (IPA); Garanhuns, X/1927, Pickel s.n. (IPA); Arcoverde, Est. Exp. Do IPA, 21/VII/1971, Andrade-Lima 71-6318 (IPA).

Distribuição e ecologia. Espécie com ampla distribuição nos trópicos e subtrópicos, ocorrendo na América do 


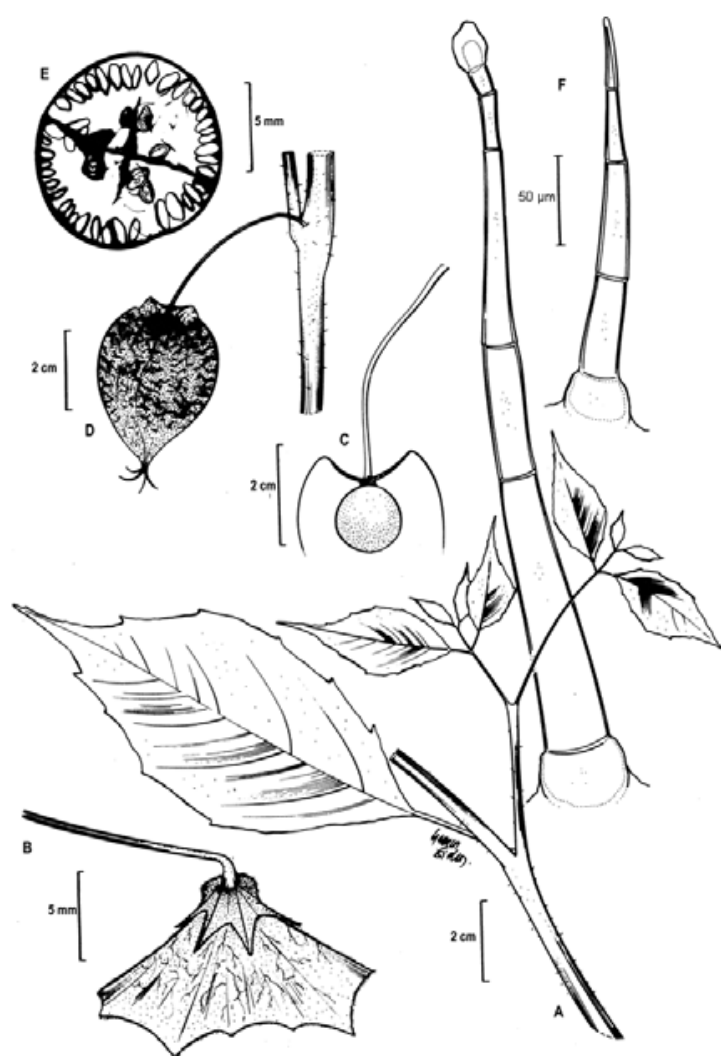

Figura 5. Physalis angulata L. (Agra et al. 2880). A. ramo; B. corola; C. esquema do fruto com cálice acrescente em secção longitudinal; D. cálice inflado; E. secção transversal do fruto; F. tricomas da lâmina foliar.

Norte, América Central, América do Sul, África, Ásia e Oceania (Hunziker, 2001). No Brasil é encontrada de norte a sul (Smith; Downs, 1966), ocorrendo principalmente em regiões semi-áridas, sendo comum o seu aparecimento em terrenos baldios e áreas perturbadas.

\section{Physalis angulata L. Sp. Pl. 1: 183. 1753.}

Sinônimos. Physalis angulata var. capsicifolia (Dunal) Griseb. Karstenia 96. 1857; Physalis capsicifolia Dunal Prodr. 13(1): 449. 1852; Physalis esquirolii H. Lév. \& Vaniot Bull. Soc. Bot. France 55: 208. 1908; Physalis lanceifolia Nees Linnaea 6: 473. 1831; Physalis linkiana Nees Linnaea 6: 471. 1831; Physalis ramosissima Mill. Gard. Dict. (ed. 8) 12. 1768.

Nomes vernaculares. Camapu, bate-testa, joá (Lorenzi; Souza, 1995), balãozinho, balão-rajado, joá-de-capote, bucho-de-rã, joá-de-balão, camaru, camambu (Kissmann; Groth, 1995), mata-fome (Correa, 1926).

Descrição morfológica. Erva, $30-50 \mathrm{~cm}$ de altura. Folhas alternas, pubescentes, tricomas simples glandulares e eglandulares; pecíolo canaliculado, 2,0-4,0 cm; lâmina $3,0-12,0$ x 1,5-3,5 cm, oblonga a oval-lanceolada,

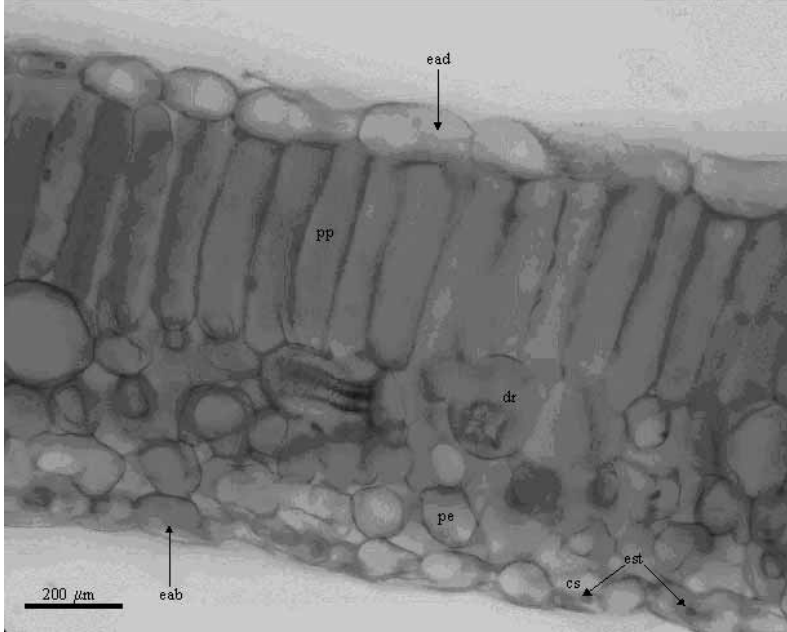

Figura 6. Physalis angulata L. (Agra et al. 2880). Secção transversal da lâmina foliar. Legendas: ead= epiderme na face adaxial; $\mathrm{pp}=$ parênquima paliçádico; $\mathrm{dr}=\mathrm{drusa} ; \mathrm{pe}=$ parênquima esponjoso; eab= epiderme na face abaxial; est $=$ estômato; $c s=$ câmara subestomática.

membranácea, ápice agudo a acuminado, base aguda ou oblíqua, margem inteira ou levemente lobada. Pedicelo cilíndrico, 0,5-1,5 cm, piloso. Flores solitárias ou em cimeiras, axilares; cálice rotáceo-campanulado, sépalas5, soldadas até \pm a metade, tubo 2,0-3,0 mm compr., lobos deltóides a lanceolados, 1,5-2,0 x 1,0 mm, cuspidados no ápice, arredondados na base, ampliados no fruto, 3,0-5,0 x 1,0-2,0 cm; corola rotáceo-campanulada, coloração amarelo-pálida, $\mathrm{o} 1 / 4$ basal do interior do tubo marrom; tubo 0,8-1,0 cm, 5-lacínios ca. 2,0 mm, triangulares. Estames5 , anteras elípticas, azuis, $1,8-2,5 \mathrm{~mm}$, dorsifixas, filetes cilíndricos, ca. 2,5 mm. Ovário subgloboso, 1,2-1,5 mm de diâmetro, bilocular, pluriovular; estilete filiforme, ca. $3,0 \mathrm{~mm}$, estigma capitado; disco hipógino, ca. $2,5 \mathrm{~mm}$ de diâmetro e $1,0 \mathrm{~mm}$ de espessura. Baga globosa, ca. $1,0-1,5 \mathrm{~cm}$ de diâmetro, envolvida pelo cálice acrescente, inflado; sementes numerosas, 0,8-1,0 mm de diâmetro, discóides, testa reticulada, ferrugíneo a marrom (Fig. 5).

Descrição anatômica. A lâmina foliar de Physalis angulata é anfiestomática e o mesofilo é heterogêneo e dorsiventral (Fig. 6). Em vista frontal, a face adaxial da epiderme apresenta células de paredes anticlinais ondeadas (Fig. 7A) e a face abaxial células igualmente ondeadas e de paredes anticlinais mais delgadas (Fig. 7B). Os estômatos são dos tipos anisocítico e esporadicamente anomocítico em ambas as faces, ocorrendo em maior número na face abaxial. Em secção transversal a epiderme é uniestratificada (Fig. 6). Na face adaxial as células apresentam paredes periclinais convexas, revestidas por uma cutícula delgada e lisa. $\mathrm{Na}$ face abaxial as células têm menor diâmetro. Os estômatos, observado em secção transversal, apresentam espessamento nas paredes internas e grande afinidade tintorial. Apenas na 

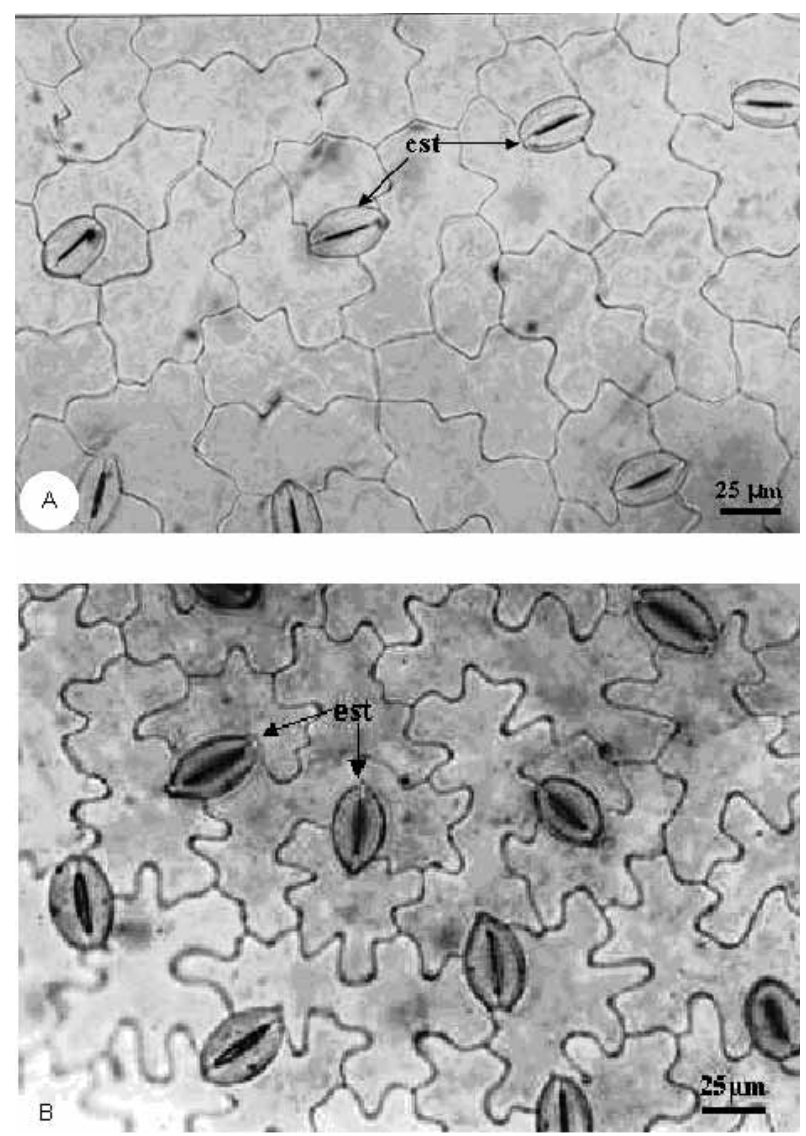

Figura 7. Physalis angulata L. (Agra et al. 2880). A-B. vista frontal da epiderme da lâmina foliar. A. face adaxial, células com paredes ondeadas e estômatos anisocíticos; B. face abaxial, células com paredes ondeadas, estômatos anomocíticos e anisocíticos. Legenda: est= estômatos.

face abaxial localizam-se um pouco abaixo do nível da epiderme. $\mathrm{O}$ parênquima paliçádico é uniestratificado e o parênquima esponjoso é formado por três a cinco camadas, com células de diversos formatos, resultando em espaços irregulares, contendo drusas no seu interior (Fig. 6).

A epiderme na região da nervura principal, quando observada tanto em vista frontal quanto em secção transversal, apresenta tricomas eglandulares, 1pluricelular, unisseriado, e tricomas glandular-estipitados, subsésseis, com a cabeça unicelular (Fig. 5F). A nervura principal (Fig. 8A) exibe contorno biconvexo, com raio menor na face adaxial, sendo proeminente na face abaxial. Adjacente à epiderme, evidencia-se o colênquima do tipo angular, com dois a três estratos celulares na região periférica de ambas as faces. O parênquima fundamental é constituído por células esféricas e hexagonais. O sistema vascular é formado por um único feixe bicolateral semicircular, com numerosos elementos de vaso dispostos radialmente, e com células floemáticas organizadas em cordões de cinco a sete estratos celulares.

O pecíolo (Fig. 8B), em secção transversal, exibe contorno biconvexo, com duas costelas laterais,
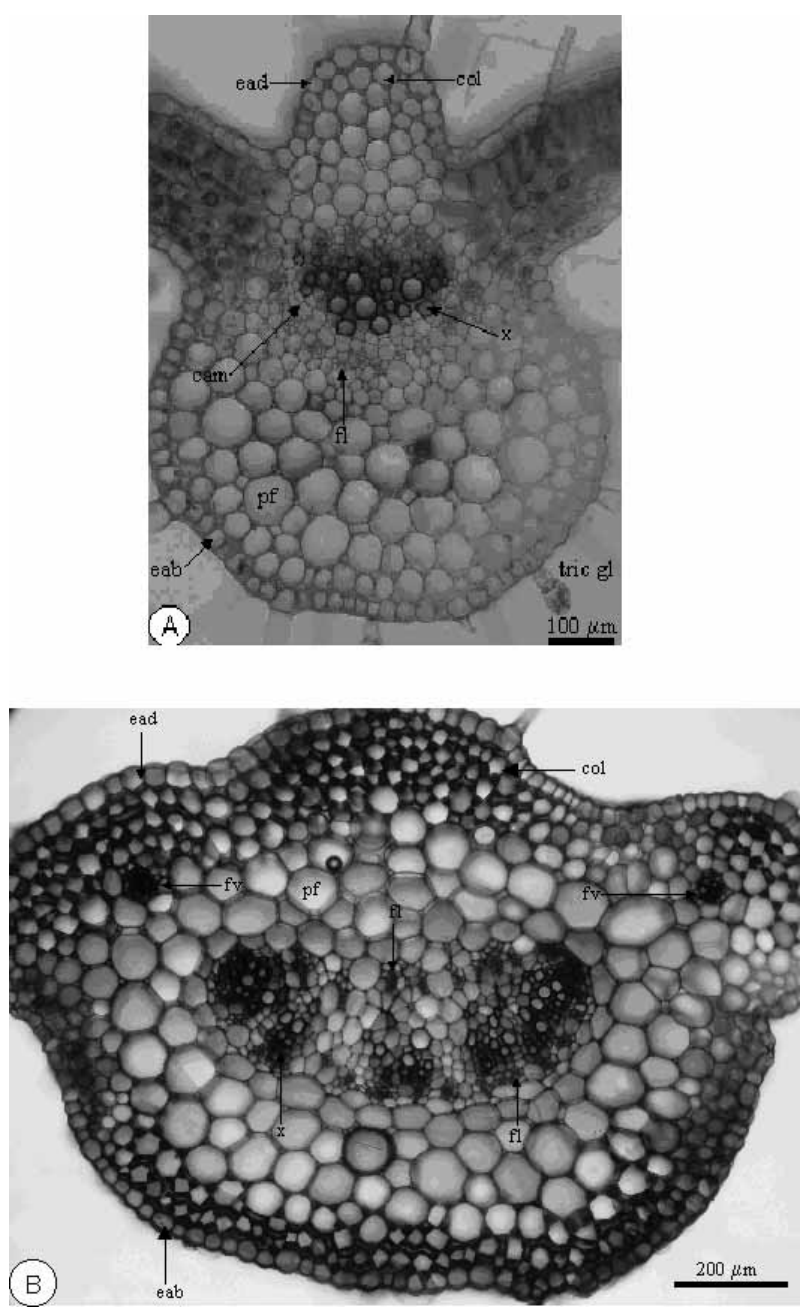

Figura 8. Physalis angulata L. (Agra et al. 2880). A. secção transversal da nervura principal, evidenciando um feixe vascular bicolateral. B. secção transversal do pecíolo, região mediana, com cinco feixes bicolaterais. Legendas: ead $=$ epiderme na face adaxial; col= colênquima; $\mathrm{fl}=$ floema; $x=$ xilema; cam = câmbio; $f v=$ feixe vascular; $\mathrm{pf}=$ parênquima fundamental; eab $=$ epiderme na face abaxial.

e seu diâmetro varia de acordo com a altura do corte, diminuindo em direção à região proximal. A epiderme é uniestratificada, revestida por uma cutícula lisa e delgada sobre as paredes periclinais externas. Tricomas simples e tricomas do tipo glandular-estipitado, similares aos da lâmina foliar, são observados ao longo do pecíolo, sendo em maior densidade nas folhas de plantas de sol. O córtex é preenchido pelo colênquima subepidérmico, do tipo angular, formado por dois a três estratos circulares nas camadas mais externas, e pelo parênquima fundamental, com células de contorno arredondado, seguido pelo sistema vascular. A transição das células colenquimáticas para células parenquimáticas é marcada por uma diminuição gradual no espessamento da parede destas células. A vascularização apresenta-se constituída de quatro a cinco feixes bicolaterais, dois a três grandes 
centrais, em forma de arco, e dois pequenos, laterais, arredondados, dispostos nas pequenas costelas.

Material examinado. BRASIL. Paraíba: Santa Rita, Usina São João, Tibirizinho, 12/VII/1990, Agra \& Góis 1198 (JPB); Cabaceiras, 29-30/VI/1994, Agra et al. 3112 (JPB); ibid, 06/V/1996, Agra et al. 3068 (JPB); Alagoa Grande, 04/VIII/1942, Xavier s.n. (JPB); Areia, X/1993, Agra \& Rocha 2109 (JPB); Boa Vista, 27-29/IV/1994, Agra et al. 2880 (JPB); Campina Grande, 25/VI/1978, Agra 027 (JPB), Serra Branca, 08-11/III/2002, Agra et al. 5687 (JPB). Pernambuco: Petrolina, 30/XII/1983, fl. fr., Fotius 3287 (IPA); Recife, Cidade Universitária, 27/ VII/1980, Melo s.n (IPA); Tuima, 20/I/1929, Pickel s.n (IPA).

Distribuição e ecologia. $P$. angulata possui uma distribuição neotropical, ocorrendo na América do Norte, América Central, América do Sul e Caribe (Nee, 1986). É uma planta ruderal, encontrada em terrenos baldios e áreas perturbadas ou próximo de habitações.

Nicandra physalodes e Physalis angulata podem distinguir-se pelo conjunto de caracteres morfoanatômicos apresentados na chave.

\section{Chave para separação de Nicandra physalodes e Physalis angulata}

1. Prefloração imbricado-plicada; corola rósea, acima de 2,0 cm de diâmetro; filetes geniculados na base; anteras basifixas; ovário 4-5 locular; epiderme papilosa; mesofilo sem drusas; tricomas glandular-estipitados, com a glândula apical pluricelular, bisseriada.........1. Nicandra physalodes

2. Prefloração imbricada; corola amarela, até $1,0 \mathrm{~cm}$ de diâmetro; filetes não geniculados na base; anteras dorsifixas; ovário 2-locular; epiderme não papilosa; mesofilo com drusas; tricomas glandular-estipitados ausentes

2. Physalis angulata

\section{CONCLUSÕES}

Com relação à morfologia, os caracteres reprodutivos da flor e do fruto foram os mais relevantes para a separação entre $N$. physalodes e $P$. angulata, uma vez que a morfologia dos caracteres vegetativos é similar para ambas as espécies. As duas espécies compartilham vários caracteres anatômicos, como a morfologia das células epidérmicas, os tipos de estômatos, o mesofilo dorsiventral e o número de feixes vasculares na nervura principal e no pecíolo. Entretanto, a presença de drusas no mesofilo de $P$. angulata é um caráter diferencial para esta espécie. Com relação à vascularização da nervura principal, a presença de elementos de vaso e as células floemáticas organizadas em cordões de cinco a sete extratos celulares, são comuns às duas espécies, que diferem pelo formato em forma de arco aberto em $N$. physalodes e semicircular em $P$. angulata. As duas espécies apresentam o mesmo número de feixes vasculares no pecíolo, um total de quatro, sendo dois laterais, dispostos nas pequenas costelas, e dois centrais. Entretanto, em $P$. angulata os feixes centrais podem variar de dois a três, característica não observada em $N$. physalodes. A variação no número de feixes centrais observada em $P$. angulata, também foi descrita por Vasconcellos et al. (1998), que consideraram ser esta variação resultante da intensidade luminosa a que as folhas estão expostas, sendo maior o número de feixes nas folhas de plantas de sombra. A presença de tricomas glandulares e eglandulares foi observada nas folhas das duas espécies, tanto na lâmina foliar quanto no pecíolo. Entretanto, o tipo glandular-estipitado, com a porção apical pluricelular, bisseriada, foi observado apenas em $N$. physalodes. Além disso, observou-se uma sutil variação na densidade de tricomas no pecíolo das folhas, sendo menor nos indivíduos de sombra.

\section{AGRADECIMENTOS}

À Coordenação de Aperfeiçoamento de Pessoal de Nível Superior (CAPES) e ao Conselho Nacional de Desenvolvimento Científico e Tecnológico (CNPq) pelas bolsas concedidas às autoras; José Maria Barbosa - Filho, Diretor de Pesquisa do Laboratório de Tecnologia Farmacêutica Prof. Delby Fernandes de Medeiros, pelo apoio pessoal e institucional; George Sidney Baracho pelas ilustrações; Tania Sarmento e Bagnólia Araújo pela revisão do manuscrito; aos revisores da RBF pelas sugestões; Dulce G. Oliveira pelo apoio técnico.

\section{REFERÊNCIAS}

Agra MF 2000. Revisão taxonômica de Solanum sect. Erythrotrichum Child (Solanaceae). São Paulo, 292p. Tese de Doutorado - Instituto de Biociências, Universidade de São Paulo.

Agra MF, Rocha EA, Formiga SC, Locatelli EM 1994. Plantas medicinais dos Cariris Velhos, Paraíba. Parte I: subclasse Asterideae. Rev Bras Farm 75: 61-64.

Barriga HG 1975. Flora medicinal de Colombia. Tomo tercero. Bogotá: Instituto de Ciências Naturales.

Basílio IJLD, Nurit K, Baracho GS, Agra MF 2003 Caracterização morfo-anatômica de Spigelia anthelmia 1. (Loganiaceae), espécie da medicina popular na Paraíba, Brasil. Rev Nordestina Biol 17: $11-22$.

Brummitt RK, Powel CE 1992. Authors of plant names. Royal Botanic Gardens, Kew.

Cabral SCM, Agra MF 1998. Etnomedicina e farmacobotânica das Capparaceae da caatinga paraibana, Brasil. Rev Bras Farm 79: 2-6.

Cabral SCM, Agra MF 1999. Estudo farmacobotânico comparativo entre Tabebuia impetiginosa (DC.) Standl. e Tabebuia aurea (Manso) S. Moore. (Bignoniaceae). Rev Bras Farm 80: 39-40.

Correa MP 1926. Dicionário das plantas úteis do Brasil e 
das exóticas cultivadas. Rio de Janeiro: Imprensa Nacional, v.1.

Correa MP 1974. Dicionário das plantas úteis do Brasil e das exóticas cultivadas. Rio de Janeiro: Imprensa Nacional, v.5.

Duke JA, Vasquez R 1994. Amazonian ethnobotanical dictionary. Florida: CRC Press, 215p.

Dunal MF 1852. Solanaceae. In De Candolle AC (ed.). Prodromus Systematis Naturalis Regni Vegetabilis 13: 1-690.

Fahn A 1974. Plant anatomy. 2a . ed. Great Britain: Pergamon Press.

Forman L, Bridson D 1989. The herbarium handbook. Great Britanic: Royal Botanic Gardens, Kew.

Freitas PF, Agra MF 2002. Etnomedicina e farmacobotânica das Convolvulaceae da caatinga paraibana, Brasil. Rev Bras Farm 83: 57-65.

Hasrat JA, De Backer JP, Vauquelin G, Vlietinck AJ 1997. Medicinal plants in Suriname: Screening of plant extracts for receptorbinding activity. Phytomedicine 4: 59-65.

Hunziker AT 2001. The genera of Solanaceae. Ruggell: A.R.G. Gantner Verlang K.G.

Kissmann GK, Groth D 1995. Plantas infestantes e nocivas. Tomo III. São Paulo: BASF.

Leal CKA, Agra MF 2005. Estudo farmacobotânico comparativo das folhas de Jatropha molissima (Pohl) Baill. e Jatropha ribifolia (Pohl) Baill. (Euphorbiaceae). Acta Farm Bonaerense 24: 5-13.

Lorenzi H, Souza HM 1995. Plantas ornamentais do Brasil, arbustivas, herbáceas e trepadeiras. Nova Odessa: Editora Plantarum.

Metcalfe CR, Chalk L 1979. Anatomy of the dicotyledons. Oxford: Claredon Press, v.1.

Nee M 1986. Solanaceae I. In Flora de Veracruz. fasc. 49. Xalapa, Veracruz: Inst. Nac. de Investigaciones sobre Recursos Bióticos.

Ribeiro IM, Silva MTG, Scares RDA, Stutz CM, Bozza M, Tomassini TCB 2002. Physalis angulata L. antineoplasic activity, in vitro, evaluation fromit's stems and fruit capsules. Rev Bras Farmacogn 12(Supl): 21-22.

Romeike A 1965. Occurrence of hygrine in the roots of Nicandra physalodes. Pharmazie 20: 738-739.

Romeike A 1966. Presence of tropinone in Nicandra roots. Naturwissenschaften 53: 82-.

Sendtner O 1846. Solanaceae, Cestrinae. In Martius CFP (ed.) Flora Brasiliensis, n.10, tab. 1-20, p.1-227.

Silva KN, Agra MF 2002. Etnomedicina e farmacobotânica das Passifloraceae da caatinga Paraibana, Brasil (Passifloraceae). In Souza MFV (org.) Iniciados. v. 8. UFPB. João Pessoa: Ed. Universitária, p.33-45.

Silva KN, Agra MF, Baracho GS 2002. Estudo etnomedicinal e farmacobotânico comparativo entre Passiflora foetida L. e Passiflora cincinnata Mast. (Passifloraceae). Rev Bras Farm 83: 51-55.

Smith LB, Downs RJ 1966. Solanáceas. In Reitz PR. Flora ilustrada catarinense. Itajaí: Herbário Barbosa Rodrigues.

Tomassini TCB, Barbi NS, Ribeiro IM, Xavier DCD 2000. Genus Physalis- A revision of withasteroids. Quim Nova 23: 47-57.

Vasconcellos AG, Gomes DMS, Esquibel MP 1998. Plasticidade anatômica de Physalis angulata L. (Solanaceae) em função da intensidade luminosa. Leandra 13: 1727. 